\title{
EL DERECHO HUMANO AL TRABAJO Y EL EJERCICIO PROFESIONAL DE LOS EXTRANJEROS. EL PUNTO DE VISTA DE LOS TRIBUNALES MEXICANOS
}

\author{
THE HUMAN RIGHT TO WORK AND THE PROFESIONAL EXERCISE OF \\ FOREIGNERS. THE POINT OF VIEW OF THE MEXICAN COURTS
}

\section{Resumen}

$\mathrm{E}$

$n$ el presente artículo se presenta un panorama retrospectivo describiendo cómo los tribunales mexicanos han visto y tratado a los extranjeros en torno al derecho al trabajo y su ejercicio profesional. La perspectiva es la de los derechos humanos. Este apartado ha sido reformulado por medio de las resoluciones de los tribunales federales en torno a ese derecho, que les ha sido negado a los destinatarios, generalmente, médicos, deportistas y artistas, vulnerando sus derechos humanos. Se presenta el recorrido habido en torno a tal tema a partir de la Constitución de 1917, partiendo de las resoluciones de los más altos tribunales judiciales, procurando explicar cómo han apreciado ese derecho, razonado y resuelto. Aunque, como se observará, el respeto no ha sido favorable.

Palabras clave: Derechos humanos; trabajo; extranjeros; tribunales mexicanos.

\section{Abstract}

$\mathrm{I}$ $\mathrm{n}$ this article I present a retrospective overview describing how Mexican courts have viewed and treated foreigners around the right to work and their professional practice. My perspective is that of human rights. This section has been reformulated by means of federal court decisions regarding this right, which has been denied to the recipients, generally doctors, athletes and artists, violating their human rights. I present the journey around this issue from the 1917 Constitution based on the resolutions of the highest judicial tribunals, trying to explain how they have appreciated that right, reasoned and resolved. Although, as will be seen, respect has not been favorable.

Key words: Human Rights; labor; foreign; Mexican court.

1 Miembro de número de la Academia Mexicana de Derecho Internacional Privado y Comparado. Presidente la Asociación Nacional de Profesores de Investigador Nacional. Miembro del Sistema Nacional de Investigadores del Consejo Nacional de Ciencia y Tecnología (Conacyt), nivel III. ORCID: 0000-0003-0809-5916. 


\section{Normatividad mexicana sobre el tema}

Como preámbulo conviene recordar lo que prescribe el derecho convencional internacional, nuestra constitución y las leyes secundarias.

\subsection{Derecho convencional internacional}

México es signante de varios convenios internacionales que destacan el derecho del extranjero al trabajo. Entre otros contamos con la Declaración Universal de Derechos Humanos, cuyo artículo 23 es claro al prescribir el derecho al trabajo, la libre elección del mismo, el derecho a condiciones equitativas y satisfactorias de trabajo y protección contra el desempleo; incluido el derecho a una remuneración equitativa y satisfactoria, que asegure, incluida la familia, una existencia conforme a la dignidad humana.

En sentido similar el artículo 6 del Pacto Internacional de Derechos Económicos, Sociales y Culturales obliga a los estados signantes a reconocer el derecho a trabajar, mediante un trabajo escogido o aceptado libremente y a tomar medidas adecuadas para garantizar este derecho.

Por su parte, la Convención Internacional sobre la Eliminación de todas las Formas de Discriminación Racial (artículo 5) los Estados parte se comprometen a prohibir y eliminar la discriminación racial en todas sus formas y a garantizar el derecho de toda persona a la igualdad ante la ley, sin distinción de raza, color y origen nacional o étnico, particularmente en el goce del derecho al trabajo y la libre elección del mismo.

A la vez, la Convención sobre la Eliminación de todas las Formas de Discriminación contra la Mujer (artículo 11) estipula que los Estados adoptarán todas las medidas apropiadas para eliminar la discriminación contra la mujer en la esfera del empleo, sin que para ello influya 
la nacionalidad. Asienta, incluso "el derecho al trabajo como derecho inalienable de todo ser humano".

Tal vez más extensa se encuentra en vigor la Convención Internacional sobre la Protección de los Derechos de todos los Trabajadores Migratorios y de sus Familiares (artículo 2), definiendo y particularizando diversos tipos de trabajadores, entre otros, el "trabajador migratorio", el "trabajador fronterizo", el "trabajador de temporada", "marino", el "trabajador en una estructura marina", el "trabajador itinerante", el "trabajador vinculado a un proyecto" y otros muchos más.

Agrega, a la vez, que los trabajadores migratorios tendrán en el Estado de empleo libertad de elegir su actividad remunerada (artículo 52). ${ }^{2}$

2 Solo se han citado algunos textos de derecho convencional internacional en forma ejemplificativa. Puede verse sobre el tema en Piza Rocafort, Rodolfo, "Derecho al trabajo y derechos de los trabajadores desde la perspectiva de los convenios internacionales sobre derechos económicos, sociales y culturales”, en Revista IIDH, Instituto Interamericano de Derechos Humanos, núm. 40, 2004. Correa, Eugenio, "Una propuesta para hacer viable el derecho al trabajo en México”, en Avances Tecnológicos de los Derechos Humanos, 2004. Sánchez-Castañeda, Alfredo, "El derecho al trabajo: Un derecho con perspectiva convencional y de derechos humanos", en Derechos del pueblo mexicano: México a través de sus constituciones, vol. V: secc. segunda. Transversalidad constitucional con prospectiva convencional, Comisión Nacional de los Derechos Humanos: Miguel Ángel Porrúa, 2016. Villaseñor Goyzueta, Alejandra, “El Trabajador Migrante en situación irregular como verdadero titular de Derechos Fundamentales en el ámbito Internacional”, en Damián Martín, Arturo Oswaldo (coord.), Derecho de la migración, Escuela Libre de Derecho, Centro de Investigación e Informática Jurídica, 2012.
1.2 Constitución Política de los Estados Unidos Mexicanos

En su turno, la Constitución Política Mexicana inicia prescribiendo la igualdad entre mexicanos y extranjeros, salvo los casos que la misma constitución prevé. Esto es, solo la Constitución puede prescribir distinciones entre mexicanos y extranjeros. Ninguna ley secundaria lo podría hacer. En las diferencias entre mexicanos y extranjeros solo se encuentra la prohibición para el ejercicio de ciertos cargos y funciones, que se les reserva a los mexicanos por nacimiento (artículo 32). Además, en tiempos de paz, ningún extranjero podrá servir en el ejército, ni en las fuerzas de policía o seguridad pública. Agregase, la restricción de los extranjeros para ocupar cargos de capitanes, pilotos, patrones, maquinistas, mecánicos y, de una manera general, todo el personal que tripule cualquier embarcación o aeronave que se ampare con la bandera o insignia mercante mexicana. Los extranjeros tampoco podrán inmiscuirse en asuntos políticos del país (artículo 33).

Salvo muy particulares casos previstos en la Constitución Política de los Estados Unidos Mexicanos que le restringen derechos a los extranjeros, y como regla general, el artículo 123 prescribe enfáticamente que "toda persona tiene derecho al trabajo digno y socialmente útil; al efecto, se promoverán la creación de empleos y la organización social de trabajo, conforme a la 
ley". En estos casos no se les restringe en su derecho a trabajar a los médicos, artistas, ni deportistas.

\subsection{Ley Federal del Trabajo}

Contrario a lo prescrito en la Constitución, la Ley Federal del Trabajo comienza estableciendo diversas restricciones a los derechos previstos en los tratados y constitución. Por ejemplo, el artículo 7 enfatiza que "En toda empresa o establecimiento, el patrón deberá emplear un noventa por ciento de trabajadores mexicanos, por lo menos".

La exclusión de extranjeros en los buques se reitera en el artículo 189 de la LFT, pues deben acreditar ser mexicanos por nacimiento. Prescripción similar se prevé para los tripulantes de aeronaves (artículo 216), trabajadores ferrocarrileros (artículo 246), inspector del trabajo (artículo 546), presidente de la Comisión de Salarios Mínimos (artículo 552), representantes ante esta Comisión (artículo 555), representantes de los trabajadores (artículo 556), director, asesores técnicos auxiliares (artículo 560), peritos designados por el tribunal (artículo 907), etcétera. Vamos, aquí los legisladores obviaron la igualdad prescrita en los tratados internacionales y la Constitución.

Me queda revisar lo que han resuelto nuestros tribunales sobre el particular, que, como se observará, han ido más allá, al imponer mayores restricciones al derecho al trabajo, vulnerando, con ello, derechos humanos.

\section{El derecho al trabajo como un dere- cho humano}

Aunque este estudio no se enfoca precisamente en explicar qué son los derechos humanos, debo decir que se trata del apartado tomado en cuenta como premisa mayor para el desarrollo de la presente investigación. Me detengo con algunas ligeras anotaciones preliminares en torno al derecho al trabajo de los extranjeros en México.

Para Federico Arcos Ramírez:

[...] el derecho al trabajo, entendido como la libertad de trabajar y, sobre todo, el derecho de acceder a un puesto de trabajo en igualdad de condiciones, sin discriminaciones, pueden ser considerados como ese mínimo definitivamente garantizado. No en vano, la misma consideración del derecho al trabajo, en todo su contenido posible, como un principio, como un mandato de optimización, supone, no solo que algo debe ser perseguido en la mayor medida posible, sino que también exige una satisfacción mínima de ese objetivo que viene a configurarse como una regla. Que dicho mínimo sea o no lo que se conoce como el contenido esencial de los derechos fundamentales es un interrogante que cuya respuesta trasciende, con mucho, las modestas ambiciones de este trabajo. ${ }^{3}$

3 Arcos, Ramírez, Federico, "La naturaleza del derecho al trabajo como derecho social fundamental", 
Tal derecho se suele presentar bajo el argumento pro-homine y como un derecho a la libertad, propio de los derechos fundamentales. De igual forma, suele aludirse al mismo como un derecho inherente o consustancial a la persona humana, aunque, a mi parecer, se trata de un derecho que deriva del derecho mismo. En general, de la voluntad del gobernante. Se le encuentra, principalmente en los tratados internacionales, que fijan una directriz que se debe seguir, aunque, de hecho y conforme a las leyes secundarias, conforme a lo que al gobernante en turno se le ocurre.

No hay que olvidar que los trabajadores migrantes no migran por placer, sino por necesidad. Luego, en consecuencia, la premisa mayor prescribe igualdad entre mexicanos y extranjeros, salvo lo que tratados y constitución pudieran establecer.

\section{Políticas del Gobierno}

A diferencia del siglo XIX en que México se abrió en lo jurídico para recibir extranjeros, en el XX las políticas cambiaron, bajo un enfoque xenófobo.

México ha sido punto de paso de migrantes hacia EUA. No todos han llegado, y muchos aquí se han quedado. En la actualidad, encontramos extranjeros centroamericanos en la selva lacandona mexicana. Conforme a las políticas de la Revolución mexicana, estas cambiaron

en Cuadernos Electrónicos de Filosofía del Derecho, núm. 3-2000. a lo habido en el siglo anterior. Adriana González Arias nos explica que:

El carácter nacionalista de la revolución tenía una clara retórica contra intereses económicos extranjeros, por lo que creció un discurso oficial de animadversión especialmente hacia españoles y estadounidenses. ${ }^{4}$

Desde 1917, la SCJN sustentó el criterio según el cual la nacionalidad mexicana es un requisito necesario para trabajar, criterio que no solo se estableció en la ley de extranjería, sino que también llegó a la primera Ley Federal del Trabajo. Solo a falta de mexicanos cabría la posibilidad de contratar a extranjeros. ${ }^{5}$ Evidentemente, se trató de un criterio político. Incluso, flota aun en el ambiente, una generalidad de personas y de juristas, que la nacionalidad mexicana es una condición para disfrutar del derecho al trabajo.

Tales directrices prohibitivas obedecieron para congraciarse con los trabajadores que cotidianamente protestaban debido a las circunstancias en que vivían. En 1921, en reuniones de la Confederación Revolucionaria Obrero Mexicana (CROM) y la Confederación General de Trabajadores (CGT), se inició una lucha contra los detentadores del capital. Inicialmente con

\footnotetext{
4 González Arias, Adriana, et al., Procesos migratorios en el occidente de México, México: ITESO, 2017.

5 Pleno, SJF, 5. época, 24 de diciembre de 1917, registro: 292524.
} 
Lombardo Toledano con dirección comunista y, posteriormente (una vez destronado) siguieron con Luis Napoleón Morones, líder de la CROM. Con esta agrupación, surgió la política del "colaboracionismo" con el gobierno, que, más tarde, continuaría Fidel Velázquez, con la CTM, que hábilmente se sustituyó a Lombardo Toledano, convirtiéndose en fiel colaborador del gobernante en turno.

Hacia 1926, se establecieron prescripciones especiales para el ingreso de los extranjeros, como fue un impuesto especial; se les clasificó por género, edad, analfabetismo, simpatizante de movimientos anarquistas, salud, se estableció, a la vez, un registro de ellos y se rechazó a los asiáticos. A mitad del camino, se impuso una cierta excepción para los llamados refugiados españoles. A pesar de las leyes en contra, se les dio trabajo a los extranjeros por ser mano de obra barata y sin especialización. ${ }^{6}$

Durante ese siglo XX los precedentes judiciales han atendido exclusivamente a los mexicanos para otorgarles del derecho al trabajo, restringiendo y anulando el mismo derecho a los extranjeros. Tanto en el trabajo, como en el ejercicio profesional.

El gobierno en el poder decretó en 1922 como día del trabajo al primero de mayo de cada año. En 1933, el desfile del primero de mayo se caracterizó por los vítores contra la burguesía. Con la política de entonces no se trataba de mera armonización entre tra- bajadores y patrones, sino una lucha entre ambos y contra los extranjeros. El partido comunista mexicano llevó regulares relaciones con el gobierno hasta 1935.7

Es necesario entender que por ese entonces se trataba de consolidar el poder por los gobernantes que violentamente habían asumido el poder, desde los primeros años, incluso, asesinándose los unos a los otros. Una doblegada y sumisa SCJN apoyó abiertamente las políticas del gobernante y militar en turno.

Destacan en las poquísimas resoluciones laborales de los más altos tribunales, aquellas que se han referido a la preferencia de trabajadores mexicanos en las fuentes de trabajo, con abierta y clara exclusión de los trabajadores extranjeros. En el campo del ejercicio profesional, de igual forma, se han producido varias resoluciones excluyendo a los extranjeros, como enseguida paso a presentar.

\section{El Nacionalismo mexicano como pre- texto para negar el Derecho del Trabajo}

Si Ramón López Velarde inició en la literatura un nacionalismo al escribir lo que veía a su alrededor y en forma cariñosa a su patria, los políticos también quisieron convertirse en "nacionalistas", pero, por desgracia, llegando a metas no propiamente nacionalistas, sino de odio y rechazo a todo lo extranjero y a la perso-

$7 \quad$ Senado de la República, México y el Mundo. Historia de sus Relaciones Exteriores, T-VI, 2000 pp. 137. 
na extranjera. Surgió, así, en la política y en los políticos un falso y distorsionado nacionalismo, para presentarse como un exclusivismo, fanatismo y rechazo a los extranjeros. Como es sabido, lo que es exclusivo, por lo general se convierte en favoritismo, intransigencia y arbitrariedad, sobre todo, cuando proviene de prejuicios.

Figura importante, en esos momentos iniciales fue Plutarco Elías Calles, aquel que construyó el estado mexicano del siglo XX, a partir del partido político que creó y gobernó todo ese siglo bajo la denominada dictadura perfecta (un partido de Estado). Ceguera e intransigencia hacia lo extranjero introdujeron, en lo político un derecho exclusivo de los mexicanos para trabajar. A ningún extranjero se le concedió el derecho a trabajar en el país.

Se entronizó un intervencionismo estatal y una política corporativista para mantener el régimen, recurriendo a leyes y normas caracterizadas como si fueran de aplicación inmediata, impidiendo la apertura y el juego conflictual mediante el rechazo al extranjero a un derecho a trabajar. Se les calificó como normas de orden público, por lo tanto, indisponibles. Las voces defensoras del régimen calificaron a estas políticas como propias del nacionalismo mexicano.

El argumento seguido ha sido la protección de los mexicanos. La expresión más conocida es "si a un extranjero se le da trabajo, tal trabajo se le niega a un mexi- cano". Sin duda alguna se trata de un enfoque político proteccionista y populista.

Las políticas proteccionistas no solo quedaron en la restricción y sustitución de importaciones, sino en la restricción del trabajo a ciertas personas, incluso, en la restricción al salario, pues se evitó que las empresas extranjeras pudieran competir, pagando salarios más altos.

Permea, incluso, una política de "defensa de los mexicanos", mediante el sacrificio de los derechos de los extranjeros a trabajar. Una mal entendida ideología política subyacente conduce a normas de orden público, incluso de derecho social y "revolucionario". Ese ha sido el gran peso y razón que ha llevado a los legisladores a una cómoda posición convenenciera que ha sometido a los juzgadores a los caprichos del gobernante en turno. Raramente los especialistas y estudiosos mexicanos han puesto atención sobre este punto.

\section{Preferencia de los trabajadores mexi- canos}

Como regla general, los tribunales mexicanos han sustentado el criterio según el cual deben preferirse a los trabajadores mexicanos por sobre los extranjeros. Como lo explicaré, la nacionalidad del trabajador ha sido el principal argumento y no precisamente las realidades de la población que habita el país. Sientan con esto, una premisa que pugna con el texto constitucional. 
Esta exclusión ha sido, desde 1917, el sentido generalizado de las decisiones judiciales como paso a explicar mediante algunos ejemplos agrupados en torno a específicos temas del derecho obrero patronal.

\subsection{Fuentes de trabajo}

La escasez de fuentes de trabajo durante la mayor parte del siglo XX, especialmente durante la época de la gran depresión de 1929 en EUA fue una variable que cabe tomarse en consideración para explicarnos el porqué solo a los mexicanos se le reconocieran las únicas fuentes de trabajo existentes. Al efecto, Luz María Martínez nos explica que:

\section{En la Segunda Convención Nacional de} Migración, celebrada en febrero de 1931, se votó la prohibición absoluta de la inmigración de trabajadores extranjeros en atención a la crisis económica. ${ }^{8}$

A instancia de algunos trabajadores, los altos tribunales resolvieron que los patrones debían despedir a los trabajadores extranjeros a pesar de que ya estuviesen trabajando, comenzando con los menos antiguos. ${ }^{9}$ Esto es, se conformó un programa político dedicado a los trabajadores extranjeros consistente en que fueran

8 Martínez Montiel, Luz María, Inmigración y diversidad cultural en México, México, UNAM, 2005, p. 69.

9 Segunda Sala, SJF, 5. ${ }^{a}$ época, AR 3845/33, 21 de noviembre de 1934, registro: 336188. Segunda Sala, SJF, 5. ' época, AR 6412/33, 28 de mayo de 1934, registro: 336425. despedidos de las fuentes de trabajo que tenían con anterioridad.

La problemática que aqueja la normatividad del derecho del trabajo mexicano deriva de datos o hechos más complejos. Con motivo de la revolución armada iniciada en 1910, varios mexicanos habían emigrado a EUA, país que en 1917 reaccionó con la llamada Ley Burnett y luego la creación de la Border Patrol en 1924. Hacia 1929, con motivo de la crisis económica en EUA, la oferta de empleo cesó y varios mexicanos tuvieron que regresar. El desempleo en México aumentó e, incluso, se agravó por las repercusiones de la crisis en EUA. Bajaron las exportaciones mexicanas al extranjero y se generaron diversos problemas económicos en México. Sin duda, fueron estas otras variables las que también influyeron en la preferencia de los trabajadores mexicanos. En estos problemas, cabe recordar la política antichina enarbolada por Plutarco Elías Calles. Odiaba que los chinos trabajaran lavando ropa, perjudicando con ello a las mujeres sonorenses.

\subsection{Porcentaje de trabajadores extranjeros}

Tanto en la Constitución como en la primera Ley Federal del Trabajo de 1931 solo se admitió un porcentaje máximo de trabajadores extranjeros en las fuentes de trabajo. Contra esa ley, los tribunales comenzaron a recibir diversas demandas signadas por los patrones o empresas, considerándola les afectaba, pues no que- 
rían dar por terminados los contratos de trabajo que ya habían celebrado con trabajadores extranjeros. ¿Qué hacer con trabajadores ya empleados?

Los más altos tribunales respondieron rechazando los reclamos de los patrones. Los tribunales argumentaron que esa ley no producía una pérdida de derechos patrimoniales al patrón. ${ }^{10}$ La SCJN adujo que los patrones no resultaban afectados al retirárseles a los trabajadores extranjeros, ya que existían trabajadores mexicanos. Lo que indirectamente puede entenderse como una discriminación hacia los extranjeros.

\subsection{Organización de trabajadores}

Una estrategia que funcionó para el control de los trabajadores y apoyo del gobierno en turno fue el sindicalismo. Hasta antes de la Constitución de 1917, se había constituido la Casa del Obrero Mundial y, aunque su vida fue efímera, su influencia marcó uno de los factores reales del poder que adelante habrían de tener los trabajadores mexicanos en la política, especialmente su fuerza en las decisiones judiciales, legislativas y administrativas.

La creación posterior de la CROM, pero especialmente las políticas de los presidentes Obregón y Calles marcaron un elemento de importancia. Por esa época, el discurso oficial se basaba en el nacionalis-

10 Cuarta Sala, SJF, 5. época, 7 de febrero de 1931, registro: 383954 . Segunda Sala, SJF, 5. época, 5 de octubre de 1932, registro: 336929. Cuarta Sala, SJF, 5. época, 24 de enero de 1935, registro: 383295. mo o nacionalismo revolucionario, como se le llamó. Tanto Obregón como Calles procuraron unificar la mayor cantidad de grupos revolucionarios, destruyendo los contrarios. El gobierno logró consolidar el corporativismo obrero. Los líderes de los trabajadores fueron premiados con puestos en el mismo gobierno. Una norma, no escrita, les dio a líderes de los trabajadores y de los campesinos una cuota en el poder. Una férrea política centralista y presidencialista consolidó un partido político en el que, como premio, hizo participar a los líderes de los trabajadores mexicanos, como diputados, senadores, gobernadores, presidentes municipales, regidores, etcétera.

Con Lázaro Cárdenas en la presidencia, se adoptó una política de intolerancia y de extremos al lograr un mayor corporativismo. Dio mayor apoyo a los trabajadores, a cambio de apoyo al gobierno en turno, incluso, enfrentando a los trabajadores contra los propios empresarios. El sindicalismo adquirió gran fuerza y desde entonces vino funcionando como apoyo al gobierno central a cambio de prebendas a sus líderes. Con el respaldo del gobierno cardenista se creó la CTM, que centralizó a todos los trabajadores del país, pilar del partido político en el poder y del gobierno mismo. Esto sirvió para estabilizar al gobierno. Quienes no estuvieron con el gobierno y sus políticas fueron reprimidos. Basta recordar las represiones a los ferrocarrileros en 1959, los movimientos 
magisteriales de esa época, las disidencias sindicales de 1971 a 1974 con los electricistas, maestros y petroleros, o la represión de 1968, el impedimento para constituir sindicatos independientes, pues todos debían seguir la directriz del sempiterno líder Fidel Velázquez, que durante medio siglo encabezó la CTM.

\subsection{Marinos mercantes}

Casi inmediatamente después de la promulgación de la Constitución de 1917, la SCJN sustentó el criterio que reiteró la preferencia de los trabajadores mexicanos por sobre los extranjeros. Cabe anotar que por ese entonces aún no se expedían las leyes del trabajo.

La primera resolución se dictó en diciembre de 1917 y les dio preferencia a los marinos mercantes mexicanos. Aunque, dijo el tribunal, a falta de ellos podrían embarcarse a las personas extranjeras avecindadas en México. Ahí se estableció una preferencia por los trabajadores de nacionalidad mexicana, lo que no parece que esto prescribiera el entonces vigente Código Civil que regulaba en contrato de trabajo.

\subsection{Filosofía política proteccionista}

Frente a las instancias de los patrones y los trabajadores, los tribunales conformaron el principio político conforme al cual se fijó la preferencia de los trabajadores mexicanos. Por un lado, se obligó a los patrones a contratar exclusivamente a tra- bajadores mexicanos y, por otro, se facultó a los trabajadores mexicanos a exigir que solo ellos podían ser los contratados. Por lo que hace a los trabajadores extranjeros, a estos se les negó el derecho a trabajar, salvo casos excepcionales que, tiempo después se establecieron, a fin de amoldarse a los momentos y circunstancias.

La SCJN para apoyar este enfoque político, lo respaldó argumentando que, así como la política de los estados es esencialmente proteccionista, así también debe ser la política con relación a los trabajadores, esto es, una política proteccionista a favor de los trabajadores mexicanos. Se puede admitir alguna excepción, dijo la Corte, pero solo en base a reciprocidad, siguiendo una recomendación de 1919 carente de fuerza positiva. ${ }^{11}$ En este sentido, a pesar de la falta de tratados internacionales, se asentó, por parte de los tribunales, que en México el derecho al trabajo tenía que cobijarse bajo una política proteccionista. ${ }^{12}$

El pensamiento político imperante pareció suavizarse en una tesis, cuando la

11 Cuarta Sala, SJF, 5. época, AR 2840/35, 24 de enero de 1935, registro: 383294.

12 Aquí la SCJN tomó en consideración la Conferencia Internacional del Trabajo de la Sociedad de las Naciones en la sesión celebrada en Washington el 29 de octubre de 1919. En esta Conferencia se asentó: "la Conferencia General recomienda que cada uno de los miembros de la Organización Internacional del Trabajo, aseguren, bajo reciprocidad, en las condiciones convenidas entre los países interesados, a los trabajadores extranjeros, ocupados en sus territorios, y a los familiares, el beneficio de sus leyes y protección obrera, así como el goce de derechos de asociación, reconocidos en los límites de las leyes, a sus propios trabajadores". 
recién creada Cuarta Sala de la SCJN (especializada en materia de Derecho del trabajo) resolvió que no se podía retirar de su puesto al extranjero para dárselo a un mexicano, sino que se debía esperar hasta que ese extranjero enseñara a un trabajador mexicano para que fuera capaz de desempeñarlo. ${ }^{13}$ En realidad, esta no fue una tesis contra la política proteccionista del gobierno, sino de conveniencia: preparar al trabajador mexicano.

Esto es, que el extranjero podía quedarse en la fuente de trabajo por un específico periodo de tiempo, pero con la condición de que enseñara a un mexicano a realizar la labor en la que era experto ese trabajador extranjero.

\subsection{Privación de cargos a los extranjeros}

A pesar de que ya eran mexicanos por naturalización, la SCJN llegó a resolver que a los mexicanos naturalizados también se les debía privar de determinados cargos, que no eran los listados en la Constitución. ${ }^{14}$

\subsection{Legitimados para reclamar la aplicabili-} dad de la ley

Ampliando el sentido de la legitimación para accionar ante los tribunales, tema hasta entonces no visto, se resolvió que la tutela a los trabajadores mexicanos no podrían hacerla valer las autoridades, sino

13 Cuarta Sala, SJF, 5. época, 25 de septiembre de 1936, registro: 381520.

14 Pleno, SJF, 5. época, 24 de diciembre de 1917, registro: 292522. también las personas que se consideren desplazadas por los extranjeros, pues estas, tienen el derecho de demandar en amparo a las autoridades de población que permitieron la entrada de los extranjeros. ${ }^{15}$ Lo que resulta altamente preocupante, pues la resolución vino hasta 1973, con una nueva ley del trabajo, que nada de esto decía.

Esto es, que para hacer efectiva una amplia política proteccionista a favor de los trabajadores mexicanos, que venía de cincuenta años atrás, no solo podía hacerse efectiva la tutela ante los tribunales del trabajo, sino también mediante los juicios constitucionales por medio de los que los particulares (trabajadores que se sintieren desplazados). En casos como estos, los mexicanos podrían demandar a las autoridades poblacionales que permitieron el ingreso al país de trabajadores extranjeros.

\subsection{Suspensión de la relación laboral}

En 1947, la SCJN resolvió un caso en el que calificó un hecho como suspensión de la relación del trabajo, mientras que la empresa mexicana descentralizada Petróleos Mexicanos la había estimado como una rescisión de la relación. Resulta importante la tesis porque el reclamante fue una persona de nacionalidad italiana, al recurrir a medios calificatorios del supuesto.

Con motivo de la Segunda Guerra Mundial, durante la cual México declaró la

15 Tribunales Colegiados de Circuito, SJF, 7. época, AR 751/72, 9 de abril de 1973, registro: 255887. 
guerra a Italia, entre otros países, el presidente de la república expidió una resolución, conforme a la cual a la entonces nueva y nacionalizada empresa Petróleos Mexicanos le rescindió el contrato de trabajo a un súbdito de nacionalidad italiana. Este súbdito fue notificado y separado de su trabajo el día 2 de julio de 1942.

Mucho tiempo después, el 29 de abril de 1944, el presidente de la república dictó otro acuerdo dejando sin efecto su acuerdo anterior. Apoyado en esto, el extranjero demandó su reinstalación en el trabajo afirmando que su situación jurídica volvió a ser la misma que tenía hasta antes de las medidas de emergencia adoptadas. Según la SCJN, la resolución del ejecutivo solo había implicado una suspensión en el contrato de trabajo del quejoso, pero esa suspensión no significaba la terminación del contrato de trabajo del súbdito extranjero.

Por lo anterior, continuó la SCJN, Petróleos Mexicanos, aunque no debió rescindir el contrato de trabajo, rescindió el mismo. En consecuencia, desde esta fecha nació la acción del quejoso para reclamar tal rescisión, acción que no se ejercitó dentro del plazo legal, por lo que prescribió el derecho del trabajador. Recordemos que el italiano presentó su demanda hasta después de que el ejecutivo dictó su acuerdo anulatorio. ${ }^{16}$

Como se observa, el alto tribunal recurrió a un argumento en el que "le compuso

16 Cuarta Sala, SJF, 5. época, 6 de noviembre de 1947, registro: 370932. la plana a Pemex" (aunque dijo haber rescindido, lo despidió). Corrigió a la empresa para negarle al extranjero el derecho a ser reinstalado. Ello se tradujo como cuestión real en hecho de negarle el trabajo a un extranjero, a pesar de la expectativa del trabajador.

\subsection{Sanciones}

Para 1930, la disposición legal preferencial había afectado a unos cuarenta mil norteamericanos ocupados por empresas petroleras, mineras, electricistas y de ferrocarriles. ${ }^{17}$

El principio general sustentado, y auspiciado por los tribunales, afirmó que los trabajadores mexicanos podían ser contratados antes que los extranjeros, con ello dio la posibilidad de que un específico y máximo porcentaje de extranjeros pudiera ser contratado. No obstante, cuando un tribunal en Tamaulipas clausuró una empresa que tenía ocupados un porcentaje mayor de extranjeros del permitido por la ley, la SCJN reaccionó resolviendo que la clausura de la empresa no era la sanción correcta, a pesar de que la empresa era propiedad de extranjeros. ${ }^{18}$

Aunque ciertamente la ley no establecía la clausura de la empresa o fuente de trabajo como sanción, los altos tribunales tampoco confirmaron la decisión del tri-

17 Senado de la República, México y el Mundo. Historia de sus Relaciones Exteriores, t. VI, p. 124.

18 Cuarta Sala, SJF, 5. época, 17 de octubre de 1935, registro: 382069 . 
bunal inferior. Tal vez por esa época ya se tenía una mayor conciencia de que se debe procurar evitar al máximo el cierre de las fuentes de trabajo.

En 1944, se llegó a estimar la actividad que se venía realizando por los mismos tribunales como una política de orden público. En una resolución el tribunal ordenó a una empresa despedir al trabajador extranjero, sin que "valga que ignoraba su nacionalidad”. Incluso la empresa o patrón que lo contrató debió ser sancionada, pues antes de contratar a un trabajador debe cerciorarse de "la legalidad de la permanencia del trabajador extranjero". ${ }^{19}$

Esto es, que para hacer efectiva la política proteccionista se introdujo la amenaza-sanción, con el fin de que los patrones evitaran contratar trabajadores de nacionalidad extranjera.

Bajo esta orientación política, la SCJN reiteró que la ley contiene disposiciones con "tendencias manifiestas a la protección de los trabajadores nacionales”, además, enfatizó que "el artículo 84 (de la entonces vigente Ley General de Población) prohibía, por tiempo indefinido, la entrada al país de inmigrantes trabajadores". Todo esto fue calificado por el más alto tribunal como de orden público, calificación que ya desde tiempo atrás se había hecho. ${ }^{20}$

19 Cuarta Sala, SJF, 5. época, AD 8510/43, 2 de octubre de 1944, registro: 372963.

20 Senado de la República, México y el Mundo. Historia de sus Relaciones Exteriores, T-VI, 2000, p. 124.
Las sanciones no solo se limitaron a exigirles a las empresas el despido de los trabajadores extranjeros que tuvieren ocupados, sino también a multarlas. No obstante, un caso de excepción se presentó en 1949 en una resolución que le eximió de esa multa a una empresa, pues el trabajador había sido contratado con anterioridad a la vigencia de la entonces vigente Ley de Población. ${ }^{21}$ Curiosa tesis porque la Constitución desde antes de la expedición de esa ley de población ya hacía referencia a la nacionalidad de los trabajadores.

Muchísimos años después, en la reforma a la LFT, de 2019, auspiciada por el presidente López Obrador, se reiteró que al patrón que no cumpla las normas que determinan el porcentaje o la utilización exclusiva de trabajadores mexicanos en las empresas o establecimientos se le impondrá una multa por el equivalente de 250 a 2500 veces la Unidad de Medida y Actualización (artículo 993).

\subsection{Cláusula de exclusión de extranjeros}

Entrada en vigor la Ley del Trabajo de 1970, la SCJN sostuvo que aunque la ley facultaba al patrón para tener hasta un diez por ciento de trabajadores extranjeros, la prescripción que aludía a las exclusiones de extranjeros no era aplicable para el caso en que los trabajadores o su sindicato hubieran sido quienes habían contratado

21 Segunda Sala, SJF, 5. ápoca, AR 10392/49, 11 de octubre de 1950, registro: 319566. 
mediante la llamada cláusula de exclusión por admisión en el contrato colectivo de trabajo, porque en este caso, se argumentó que el patrón perdió la libertad de escoger a su personal. ${ }^{22}$

Una cláusula como esta significa que en un contrato de trabajo se establece que el patrón solo puede admitir como trabajadores a aquellos que sean miembros del sindicato. Hecho que históricamente marcó a los líderes sindicales como corruptos, pues, normalmente, "vendían" las plazas a los trabajadores necesitados.

Todavía en la actualidad la LFT (artículo 154) alude a la preferencia de trabajadores mexicanos. La reforma del 3 de julio de 1976 adicionó un párrafo para enfatizar en que "si existe contrato colectivo y este contiene cláusula de admisión, la preferencia para ocupar las vacantes o puestos de nueva creación se regirá por lo que disponga el contrato colectivo y el estatuto sindical". El artículo 155 presupone la nacionalidad del trabajador, pues establece cuando un trabajador aspire a un puesto vacante, debe solicitarlo, presentando una solicitud que incluya su domicilio y nacionalidad.

\section{Deportistas y profesionistas extran- jeros}

Además de trabajadores, la política del exclusivismo se amplió a ciertos deportistas

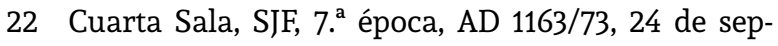
tiembre de 1973, registro: 243021. y algunos profesionistas, dejándolos sin poder trabajar. ${ }^{23}$

La ley en ambos casos, trabajadores y profesionistas, ha minimizado a los extranjeros, y los tribunales judiciales han enfatizado sobre los profesionistas médicos, así como sobre un específico tipo de deportistas.

\subsection{Ejercicio de la profesión}

La legislación secundaria prescribió que ni los trabajadores, ni los profesionistas de nacionalidad extranjera pueden ejercer su actividad en México. De esta forma los médicos extranjeros fueron excluidos del ejercicio profesional, a pesar de que nada de esto prescribía la Constitución. La Ley Federal del Trabajo (vigente y anterior) acogiendo esta política legislativa prescribe que:

[E]n toda empresa o establecimiento, el patrón deberá emplear un noventa por ciento de trabajadores mexicanos, por lo menos. En las categorías de técnicos y profesionales, los trabajadores deberán ser mexicanos, salvo que no los haya en una especialidad determinada, en cuyo caso el patrón podrá emplear temporalmente a trabajadores extranjeros, en una proporción que no exceda del diez por ciento de los de la especialidad. El patrón

23 El ejercicio profesional o cualquier otro tipo de trabajo es otra forma de laborar, pero al ejercicio profesional no se le califica, ni estudia en México dentro del derecho del trabajo. 
y los trabajadores extranjeros tendrán la obligación solidaria de capacitar a trabajadores mexicanos en la especialidad de que se trate. Los médicos al servicio de las empresas deberán ser mexicanos. No es aplicable lo dispuesto en este artículo a los directores, administradores y gerentes generales (artículo 7).

Cuando un tribunal inferior ordenó que una empresa solo podía emplear menos del diez por ciento de trabajadores extranjeros, la SCJN lo respaldó argumentando que la ley prescribía que las empresas solo pueden emplear hasta un 10 por ciento de trabajadores extranjeros, pero no que necesariamente lo tuviera que ser. En esta resolución la Corte asentó que:

[...] todos los países protegen a sus nacionales contra los técnicos extranjeros y obligan a las empresas a utilizar precisamente a nacionales, política que tiene derecho a seguir el estado mexicano, puesto que, en términos generales, no se utilizan en países extranjeros a técnicos mexicanos. $^{24}$

Sobre esta tesis cabe hacer una observación por el matiz político que la caracterizó (1. ${ }^{\circ}$ de marzo de 1938). El presidente de la república, en ese entonces, era Lázaro Cárdenas y la empresa interesada fue la

24 Cuarta Sala, SJF, 5. ápoca, AD 2/1938, 1. ${ }^{\circ}$ de marzo de 1938, registro: 380189.
Compañía Mexicana de Petróleo el Águila S. A., empresa que solo de nombre era mexicana, pues en realidad era extranjera (angloholandesa). Precisamente por el incumplimiento a la sentencia en que se insertó esta tesis fue que al presidente le sirvió de pretexto días después, para decretar la expropiación petrolera. Esto es, que en atención a la expropiación los bienes de la empresa pasaron a ser propiedad del estado mexicano. ${ }^{25}$

Cabe aclarar que las empresas extranjeras lucharon en torno a este punto con el fin de evitar que se les restringiera el porcentaje que consideraban como puestos de confianza.

Como se sabe, durante el juicio que dio lugar a esta resolución, los ánimos de los trabajadores y la empresa se habían caldeado, no obstante, se estableció que el noventa por ciento de los trabajadores mexicanos fijado en la ley, se aumentó por el más alto tribunal de justicia, disminuyéndose, por consecuencia, el porcentaje de trabajadores extranjeros permitidos.

Bajo el enfoque "derecho humanista", tan en boga al final del siglo XX, los tribunales continuaron despreciando a los extranjeros, incluso han llegado a justificar sus resoluciones debido a la falta de reciprocidad en otros países. Aunque, desgra-

25 Esta ley de expropiación apenas acababa de ser aprobada a finales de 1936. Antes las inquietudes de los petroleros extranjeros, Cárdenas les expresó que no abrigaran temores, pues no se les iba a expropiar. Senado de la República, México y el Mundo. Historia de sus Relaciones Exteriores, t. VI, 2000, p. 163. 
ciadamente, la tesis no mencionó a cuál o cuáles países se refirió.

La alegación de falta de reciprocidad solo fue un discurso gratuito, pues es sabido que como premisa para hablar de reciprocidad debe existir un específico país que obre de la misma manera como obró el gobierno mexicano y que otro país, involucrado en el caso sea el que no sea recíproco.

La SCJN resolvió en 1939 un caso en el que los profesionistas extranjeros fueron excluidos por completo como derecho de los extranjeros. Uno de los casos fue el de un médico al servicio de una empresa, a la que se le ordenó que lo despidiera. ${ }^{26} \mathrm{El}$ argumento judicial consistió en una específica calificación, pues, no se le estimó precisamente como profesionista, con naturaleza autónoma, sino como trabajador.

En 1939, la SCJN resolvió otro caso ordenando que la empresa Ferrocarriles Nacionales no estaba obligada a indemnizar a un médico extranjero al que había despedido, ya que las empresas mexicanas solo debían contratar a médicos mexicanos. Aunque careciendo la resolución de una ratio decidendi, el tribunal sostuvo que la empresa sí tuvo causa justificada para rescindirle el contrato de trabajo al extranjero, reiterando, con ello, a la nacionalidad extranjera como criterio para negarles el derecho a los trabajadores extranjeros,

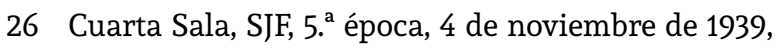
registro: 381236. pero lo más grave fue que ni siquiera a la indemnización tuvo derecho el trabajador. ${ }^{27}$

Cabe tomar en cuenta que, hasta ahora, no se encuentra establecido en la constitución general la facultad de dar por terminado o rescindido un contrato de trabajo sin la obligación de pago alguno, salvo en los casos específicamente establecidos. Tal ha sido el motivo de exponer este criterio.

Apoyado en la disposición legal que prescribe que los médicos deben de ser mexicanos, un tribunal colegiado, en 1991, resolvió que un médico extranjero que estaba al servicio de una persona moral ni siquiera podía ocupar ese cargo. ${ }^{28}$

En 2008 la SCJN volvió a reiterar la cláusula de exclusión de extranjeros al sostener que:

[...] la restricción al derecho al trabajo para el ejercicio profesional de los médicos, se encuentra justificada y es necesaria para garantizar el derecho a la salud, que puede comprender de manera específica el establecimiento de medidas para garantizar la calidad de los servicios de salud, al concretarse a exigir a los médicos que quieran practicar cirugías estéticas y cosméticas a que satisfagan condiciones mínimas necesarias de capacitación, educación, experiencia y tecnología; y que las realicen en esta-

27 Cuarta Sala, SJF, 5. época, 4 de noviembre de 1939, registro: 381236.

28 Tribunales Colegiados de Circuito, SJF, Octava época, AR 1162/91, 19 de junio de 1991, registro: 221979. 
blecimientos con condiciones sanitarias adecuadas y en donde se utilicen medicamentos y equipo hospitalario científicamente aprobados y en buen estado, es decir, a que ofrezcan servicios médicos de calidad, lo cual claramente protege el derecho a la salud. ${ }^{29}$

Las "justificantes" de los tribunales quedaron en el hecho de que se despida a un trabajador extranjero, ello no perjudica a la empresa, pues en todo caso solo afecta a los trabajadores extranjeros. También quedó claro, bajo este enfoque, que la afectación a los extranjeros no pareció importarles a los tribunales, pues, incluso, han validado el despido de esos trabajadores.

El dato que nos pone a repensar es el hecho de que los profesionistas excluidos al derecho al trabajo fueron los médicos. La pregunta que se impone es ¿por qué solo los médicos?, ¿por qué no se incluyó a ingenieros, electricistas, abogados, etcétera? Seguramente fue una razón personal del legislador para negarle el derecho a todos los médicos. No cabe en la razón más que considerar que el legislador solo introdujo a los médicos, y que aquellos que votaron su favor de una ley como esta, así lo decidieron siguiendo un criterio derivado de una mera ocurrencia, de venganza contra algún médico; en fin, un desatino propio de un cráneo hueco.

29 Primera Sala, SJF, 9. época, AR 115/2008, 21 de mayo de 2008, registro: 167377.
En fin, en la preferencia a las fuentes de trabajo por parte de nacionales mexicanos, se ha favorecido a los que poseen la nacionalidad mexicana, y prácticamente abandonando a su suerte a los trabajadores extranjeros, aun cuando ya se encuentren dentro del territorio mexicano. Al lado de esta cláusula de exclusión de médicos extranjeros, a estos también se les excluyó.

\subsection{Deportistas}

La tutela a los trabajadores mexicanos se extendió como prohibición para ciertos deportistas extranjeros, a los que se les negó el derecho a trabajar. Estos deportistas fueron calificados como trabajadores. Uno de los tribunales colegiados calificó la actividad realizada por jugadores de frontón o jai alai ${ }^{30}$ como si fuese trabajo. El alto tribunal exigió que el número de pelotaris extranjeros no debía exceder del diez por ciento del total. Al respecto afirmó que, aunque:

[...] el cuadro extranjero proporciona mayor calidad al deporte y atrae más público, es de verse que en estos casos son los intereses de los trabajadores nacionales los que tutela la ley y no los de la empresa, y que solo dando oportunidades profesionales a dichos nacionales es como podrá lograrse una mejora de los cuadros formados por ellos. ${ }^{31}$

30 Se trata de un deporte, propio de la pelota vasca, que participa en los juegos olímpicos.

31 Cuarta Sala, SJF, 5. época, 27 de febrero de 1935, registro: 383384. 
Como se observa en esta resolución, la ratio decidendi derivó de datos o elementos políticos o sociales que ni siquiera estaban en la ley, imponiéndose la muy particular del juzgador que resolvió. Aquí cabe preguntar ¿porqué de entre tantos deportistas solo a los pelotaris se les excluyó? 32

Cabe agregar, que en 2019 se adoptó una regla entre los futbolistas para ir reduciendo el número de futbolistas extranjeros. Todo, a partir de la recomendación del seleccionador nacional Gerardo Martino, durante la Asamblea Ordinaria de la Liga MX. ¿Podrá entenderse esto como una vulneración a los derechos humanos de los extranjeros?

\section{Reduciendo la prohibición}

Finalmente, en el caso de los profesionistas y algunos trabajadores, los tribunales han suavizado o anulado la prohibición en algunos casos, incluso, declarando la inconstitucionalidad de la ley prohibitiva.

Como cosa rara y excepcional, en 1935, en medio de estas políticas retrógradas, una Junta (un tribunal obrero patronal) estimó como extranjero al hijo de un extranjero que no había hecho uso de su facultad de ius optandi, al aparecer la Constitución de

32 Un dato de interés y contemporáneo al momento en que se resolvió fue el hecho de que se desató la Guerra Civil española. En México, varios pelotaris de la selección vasca se quedaron aquí (Blasco, Arezo, Aedo, Pablo Barcos, Muguerza, Zubieta, Pedro Regueiro, Luis Regueiro, Cilauren, Aguirre, Lángara y Urquiola). Gobernaba Cárdenas. Poco después, (diciembre de 1937) se clausuró el frontón México.
1917. Pero, al ser revisado en amparo este caso, la SCJN resolvió que, aunque ese trabajador no era mexicano, pues no había optado por la nacionalidad de sus padres, ese "error... no puede privarlo de las prerrogativas que señala el artículo 123 constitucional”. ${ }^{33}$ ¿Qué ocurrió?, ¿el tribunal se dolió de ese trabajador o tomó en cuenta un derecho humano? No lo sabemos.

En 1951, la SCJN dictó la primera resolución declarando inconstitucionales algunas disposiciones de la Ley de Profesiones ${ }^{34}$ que habían impuesto restricciones a los profesionistas extranjeros, marcando diferencias entre mexicanos y extranjeros..$^{35} \mathrm{In}$ cluso, uno de los beneficiados con estas resoluciones fue el conocido civilista Rafael de Pina Vara, que unos años antes había sido recibido, junto con otros inmigrantes españoles que huyeron de la Guerra Franquista. Debido a la existencia de varios criterios en sentido similar, tal criterio se convirtió en jurisprudencia definida. ${ }^{36}$

33 Cuarta Sala, SJF, 5. época, 5 de febrero de 1935, registro: 383314.

34 Segunda Sala, SJF, 5. ${ }^{a}$ época, 10 de agosto de 1951, cinco votos, registro: 318844.

35 Segunda Sala, SJF, 5. época, 29 de octubre de 1952, cinco votos, registro: 318844 . Segunda Sala, SJF, 5. ${ }^{a}$ época, AR 4062/52, 28 de noviembre de 1952, registro: 318865. Segunda Sala, SJF, 5. época, AR 547/53, 26 de junio de 1953, registro: 318608. Segunda Sala, SJF, 5. época, AR 1297/53, 12 de agosto de 1953, registro: 206569. Segunda Sala, SJF, 5. época, $1{ }^{\circ}{ }^{\circ}$ de marzo de 1954, cuatro votos, registro: 318158 . Segunda Sala, SJF, 5. época, AR 586/56, 26 de julio de 1956, registro: 316155. Pleno, SJF, 7. época, AR 3892/74, 3 de junio de 1975, registro: 232871.

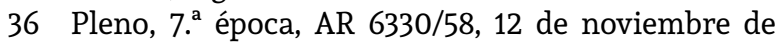
1970, registro 233721. 
En este correr, los profesionistas extranjeros, al igual que los mexicanos, tienen que obtener la cédula profesional (la patente para el ejercicio de una profesión). Aunque, tratándose de extranjeros, no es la Secretaría de Educación Pública la que debe autorizar al extranjero en su situación migratoria para el ejercicio profesional, sino la Secretaría de Gobernación. Al respecto, la SCJN resolvió que:

\section{La Dirección General de Profesiones no} debe resolver en forma definitiva que en vista de la calidad migratoria de un quejoso no era de expedírsele cédula profesional, sino que debe dictar resolución en la que haga constar que por haber cumplido el citado quejoso con todos los requisitos que marca la Ley de Profesiones, tenía derecho a la expedición de la cédula profesional, y, a lo más, que esta le sería entregada una vez que comprobase que la Secretaría de Gobernación le hubiere autorizado el cambio de situación migratoria. ${ }^{37}$

Tiempo después, los tribunales colegiados, contrariando el argumento anterior, resolvieron que no era necesario que el profesionista extranjero demuestre su calidad migratoria para que se le expida su cédula o patente. ${ }^{38}$

37 Segunda Sala, SJF, 6. ${ }^{a}$ época, AR 8137/59, 8 de agosto de 1960, registro: 267810.

38 Tribunales Colegiados de Circuito, SJF, 7. época, 1313/82, 4 de noviembre de 1982, registro: 250111.
Por lo que se refiere a la "cédula", un tribunal colegiado resolvió que el extranjero que la obtuvo, en atención a lo ordenado en un proceso de amparo, en nada le agravia que en su cédula se asiente que se otorgó en acatamiento de un juicio de amparo. ${ }^{39}$

Cambiando ahora al caso de los artistas, y aunque estos no son calificados por la ley mexicana como profesionistas (carecen de título académico), ocurre que la mayoría de los artistas, afirman ser profesionistas. Pero, independientemente de tal calificación y respecto a los artistas extranjeros, dijo la Corte, estos solo pueden trabajar en el centro de diversiones que le autorice la Secretaría de Gobernación. ${ }^{40}$

Aunque ya he explicado que a los extranjeros se les ha negado el derecho a trabajar dentro de territorio mexicano, algunas tesis han mostrado un cierto sentido más humanista, reconociéndoles tal derecho. Resoluciones que en mínima escala han tratado de balancear el rechazo al trabajo a los extranjeros. En algunos casos se ha aceptado el derecho al trabajo, en otros, no.

Estas tesis no fueron pronunciadas en la época cardenista, sino durante el gobierno de Miguel Alemán, cuya política, a diferen-

Tribunales Colegiados de Circuito, SJF, 7. ${ }^{\mathrm{a}}$ época, AR 24/83, 9 de marzo de 1983, registro: 249855 . Tribunales Colegiados de Circuito, SJF, 7. época, AR 685/83, registro: 249037.

39 Tribunales Colegiados de Circuito, SJF, 7. época, Queja 19/83, 14 de junio de 1983, registro: 249854.

40 Segunda Sala, SJF, 6. ${ }^{a}$ época, AR 1109/60, 21 de septiembre de 1960, registro: 267754. 
cia de la de Cárdenas, procuró mediar con EUA y otros países.

El argumento principal consistió en que el artículo primero constitucional establece la igualdad entre mexicanos y extranjeros. El artículo 4 (hoy 5) constitucional prescribe que a ninguna persona se le podrá impedir que se dedique a la profesión, industria o trabajo que le acomode, además, el artículo 5 prohíbe que se celebre algún convenio en el cual una persona pacte su renuncia a ejercer su profesión, industria o comercio. Los derechos solo podrán ser restringidos en los casos expresamente establecidos en la propia Constitución. En ninguna prescripción constitucional -resolvió la SCJN- se restringe el derecho al trabajo; "no puede admitirse convenio por el cual el hombre renuncie temporal o permanentemente a ejercer determinada profesión, industria o comercio". ${ }^{41}$ Pese a esta prescripción, de 1954, los extranjeros no gozan de las garantías individuales, como en ese entonces la Corte afirmó. Esta ha sido contradictoria en sus decisiones.

\section{A manera de conclusión}

En la conclusión cabe tomar en cuenta dos tópicos: el político y el propiamente jurídico.

41 Segunda Sala, SJF, 5. época, 10 de agosto de 1951, registro 318158. Segunda Sala, SJF, 5. ápoca, registro: 318844. Cinco votos, registro: 318158. Segunda Sala, SJF, 5. ${ }^{a}$ época, $1 .^{\circ}$ de marzo de 1954, registro: 318160. Pleno, AR 6330/58, 12 de noviembre de 1970, registro: 233721 .
En lo político, al avaluarse las resoluciones anteriores se llega al convencimiento de que ha habido y se ha manifestado una xenofobia sobre el trabajador y ciertos profesionistas extranjeros. Incluso la propia palabra “extranjero" llevó en México durante buena parte del siglo XX una especial carga emotiva. Esa animadversión ha reconducido a una sobreprotección al trabajador nacional, al negarles a los extranjeros el derecho a trabajar y a un despido de trabajadores extranjeros, incluso a sancionar a las empresas contratantes.

Es difícil explicar por qué la política mexicana (legisladores y jueces) solo ha tutelado a los trabajadores mexicanos excluyendo a los extranjeros, a pesar de la igualdad política pregonada. Cabría pensar en las políticas nacionalistas de la primera mitad del siglo XX, el manipuleo de los intereses de los trabajadores por parte del gobierno en turno a través de los sindicatos oficialistas, al hecho de que los únicos que pueden votar en México son los mexicanos, que estos, debido a sus pocas fuentes de trabajo, han encontrado en los extranjeros un factor de competitividad. Es posible que estos datos nos expliquen por qué han llevado a legisladores juzgadores a decidir cómo se ha hecho. Lo anterior, sin olvidar el odio y desprecio de los primeros gobiernos de México hacia la comunidad extranjera y el sometimiento del poder legislativo y judicial. 
En el aspecto jurídico debe observarse que la mayoría de todas las resoluciones que he reseñado omiten la estrategia argumentativa que las ha conducido a su resultado. La estructura del discurso que resuelve carece de elementos lógicos, comenzando porque el resolutor ignora la premisa mayor, que exige el respeto al trabajo. Recurre a pensamientos no sólidos (opiniones sin fundamentos) y a un discurso sin razones y "argumentos", sin ruta, pues solo tiende a afirmar el pensamiento del encargado del poder ejecutivo, al cual solo obedece.

Ninguna de las restricciones impuestas por legisladores y jueces tiene explicación racional. Las decisiones han obedecido más a impulsos virulentos, salvajes e irracionales de quien legisla y juzga. Como dije, los resolutores han obedecido a la imperdonable subordinación al encargado del poder ejecutivo en México.

Normalmente han ignorado la premisa de mayor importancia (la constitucional y la convencional internacional) que prevé la igualdad entre extranjeros y mexicanos.

En las resoluciones habidas ni siquiera se presenta un argumento persuasivo que procure convencer de lo que se afirma. Las expresiones solo "valen" porque las ha dictado una autoridad (son enfáticas, arbitrarias y dictatoriales), pero no porque se apoyen en el derecho que debieran acatar. $\mathrm{Al}$ abogado que llevó cada uno de estos asuntos, de nada le serviría demostrar la carencia de validez lógica y jurídica de los "argumentos" del tribunal, pues nada podría hacer. Ha resultado tan imperativa cada resolución, que jurídicamente no cabría contra ella recurso alguno. $\mathrm{Al}$ que estudia esto, solo le vale, porque denuncia las inhumanas e ilegales decisiones.

\section{Bibliografía}

Arcos, Ramírez, Federico, "La naturaleza del derecho al trabajo como derecho social fundamental", en Cuadernos Electrónicos de Filosofía del Derecho, núm. 3, 2000.

Correa, Eugenio, "Una propuesta para hacer viable el derecho al trabajo en México”, en Avances Tecnológicos de los Derechos Humanos, 2004.

González Arias, Adriana, et al., Procesos migratorios en el occidente de México, México, ITESO, 2017.

Martínez Montiel, Luz María, Inmigración y diversidad cultural en México, México, UNAM, 2005.

Piza Rocafort, Rodolfo, "Derecho al trabajo y derechos de los trabajadores desde la perspectiva de los convenios internacionales sobre derechos económicos, sociales y culturales", en Revista IIDH, Instituto Interamericano de Derechos Humanos, núm. 40, 2004.

Sánchez-Castañeda, Alfredo, "El derecho al trabajo: Un derecho con perspectiva convencional y de derechos humanos", en Derechos del pueblo mexicano: México a través de sus constituciones, vol. V: secc. segunda. Transversalidad constitucional con prospectiva 
convencional, Comisión Nacional de los Derechos Humanos, Miguel Ángel Porrúa, 2016.

Senado de la República, México y el mundo. Historia de sus relaciones exteriores, T-VI, 2000.

Villaseñor Goyzueta, Alejandra, "El trabajador migrante en situación irregular como verdadero titular de derechos fundamentales en el ámbito internacional”, en Damián Martín, Arturo Oswaldo (coord.), Derecho de la migración, Escuela Libre de Derecho, Centro de Investigación e Informática Jurídica, 2012.

Jurisprudencia mexicana

Cuarta Sala, SJF, 5. época, 5 de febrero de 1935 , registro: 383314.

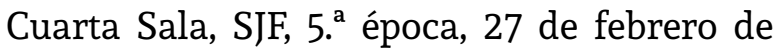
1935, registro: 383384.

Cuarta Sala, SJF, 5. ${ }^{a}$ época, AD 2/1938, $1 .^{\circ}$ de marzo de 1938, registro: 380189.

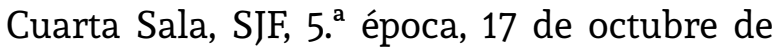
1935, registro: 382069.

Cuarta Sala, SJF, 5. época, AD 8510/43, 2 de octubre de 1944, registro: 372963.

Cuarta Sala, SJF, 5. época, 4 de noviembre de 1939, registro: 381236.

Cuarta Sala, SJF, 7. ${ }^{a}$ época, AD 1163/73, 24 de septiembre de 1973, registro: 243021.

Segunda Sala, SJF, 5. época, registro: 318844. cinco votos, registro: 318158.

Segunda Sala, SJF, 5. ${ }^{\mathrm{a}}$ época, $1 .^{\circ}$ de marzo de 1954, cuatro votos, registro: 318158.

Segunda Sala, SJF, 5. ${ }^{\mathrm{a}}$ época, $1 .^{\circ}$ de marzo de 1954, registro: 318160.
Segunda Sala, SJF, 5. época, AR 6412/33, 28 de mayo de 1934, registro: 336425.

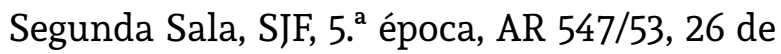
junio de 1953, registro: 318608.

Segunda Sala, SJF, 5. época, AR 586/56, 26 de julio de 1956, registro: 316155.

Segunda Sala, SJF, 5. ${ }^{a}$ época, 10 de agosto de 1951, registro 318158.

Segunda Sala, SJF, 5. época, 10 de agosto de 1951, cinco votos, registro: 318844.

Segunda Sala, SJF, 5. época, AR 1297/53, 12 de agosto de 1953, registro: 206569.

Segunda Sala, SJF, 5. época, AR 10392/49, 11 de octubre de 1950, registro: 319566.

Segunda Sala, SJF, 5. época, AR 3845/33, 21 de noviembre de 1934, registro: 336188.

Segunda Sala, SJF, 5. época, AR 4062/52, 28 de noviembre de 1952, registro: 318865.

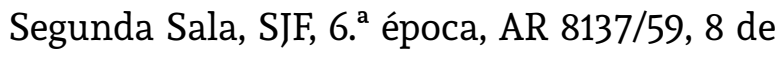
agosto de 1960, registro: 267810.

Segunda Sala, SJF, 6. época, AR 1109/60, 21 de septiembre de 1960, registro: 267754.

Pleno, SJF, 5. a época, 24 de diciembre de 1917, registro: 292524.

Pleno, SJF, 7. época, AR 3892/74, 3 de junio de 1975, registro: 232871.

Pleno, 7. época, AR 6330/58, 12 de noviembre de 1970, registro 233721.

Primera Sala, SJF, 9. época, AR 115/2008, 21 de mayo de 2008, registro: 167377.

Tribunales Colegiados de Circuito, SJF, 7. época, AR 24/83, 9 de marzo de 1983, registro: 249855 . 
Tribunales Colegiados de Circuito, SJF, Séptima época, Queja 19/83, 14 de junio de 1983, registro: 249854.

Tribunales Colegiados de Circuito, SJF, 7a época, 1313/82, 4 de noviembre de 1982, registro: 250111.

Tribunales Colegiados de Circuito, SJF, Octava época, AR 1162/91, 19 de junio de 1991, registro: 221979. 